Reference : Harrison R, Spearpoint M J. The balcony spill plume: Entrainment of air into a flow from a compartment opening to a higher projecting balcony. Fire Technology, Vol. 43, No. 4, pp.301-317, 2007. http://dx.doi.org/10.1007/s10694-007$\underline{0019-3}$

\title{
The Balcony Spill Plume: Entrainment of air into a flow from a compartment opening to a higher projecting balcony
}

Roger Harrison and Michael Spearpoint, Department of Civil Engineering, University

of Canterbury, New Zealand.

\begin{abstract}
In the design of smoke ventilation systems, a crucial input parameter for balcony spill plume calculations is the mass flow rate of gases at the spill edge. In some cases, depending upon the specific geometry, these calculations can require the entrainment of air into a flow from a compartment opening to a higher projecting balcony to be determined. Entrainment of air into these smoke flows are not well understood and the current guidance available to the designers of smoke ventilation systems is crude. This work presents a simple empirical correlation to predict the entrainment of air into these flows, and hence, the subsequent mass flow rate of gases at the spill edge. A computational fluid dynamics modelling and physical scale modelling approach was used in the analysis. In general, this work has demonstrated that the current guidance on the entrainment of air into these flows is conservative.
\end{abstract}

\section{Introduction}

The paper concerns the design Smoke and Heat Exhaust Ventilation Systems (SHEVS) for atrium buildings. This approach provides smoke and heat exhaust from the upper regions of a building to create a clear layer beneath a buoyant stratified smoke layer. The use of SHEVS is particularly important in terms of life safety and property protection. 
Atrium buildings are commonly designed such that the atrium space is connected to adjacent rooms or spaces. Rooms which connect to the atrium via unprotected openings are known as communicating spaces. If a fire were to occur in a communicating space (e.g. a shop or office unit), a horizontally moving buoyant layer of hot smoky gases will form within that space. This layer will spread laterally and flow toward the opening connecting to the atrium space. If there are no smoke control measures to confine the smoke layer to the room of origin, this horizontally moving layer will flow out of the opening. If a balcony exists beyond the compartment opening, smoke will flow beneath the balcony. The smoke flow will then rotate around the free edge of the balcony (i.e. the 'spill edge'). The smoke will then rise vertically as a plume into the atrium space and entrain large quantities of air (see Figure 1). Entrainment of air will also occur into the free ends of the plume as it rises. This type of plume is commonly known as a balcony (or a free) spill plume.

A key input parameter for balcony spill plume calculations is the mass flow rate of gases at the spill edge. This represents the mass flow rate of the horizontally flowing smoke layer at the end of the balcony prior to spilling into the atrium space. A common scenario is the presence of a downstand at a compartment opening from which a higher projecting balcony extends (see Figure 1). As smoke flows from the compartment opening and rises to form a layer beneath the balcony, entrainment of air will occur into the smoke flow. This entrainment needs to be accurately determined to predict the mass flow rate of gases at the spill edge for design purposes. 


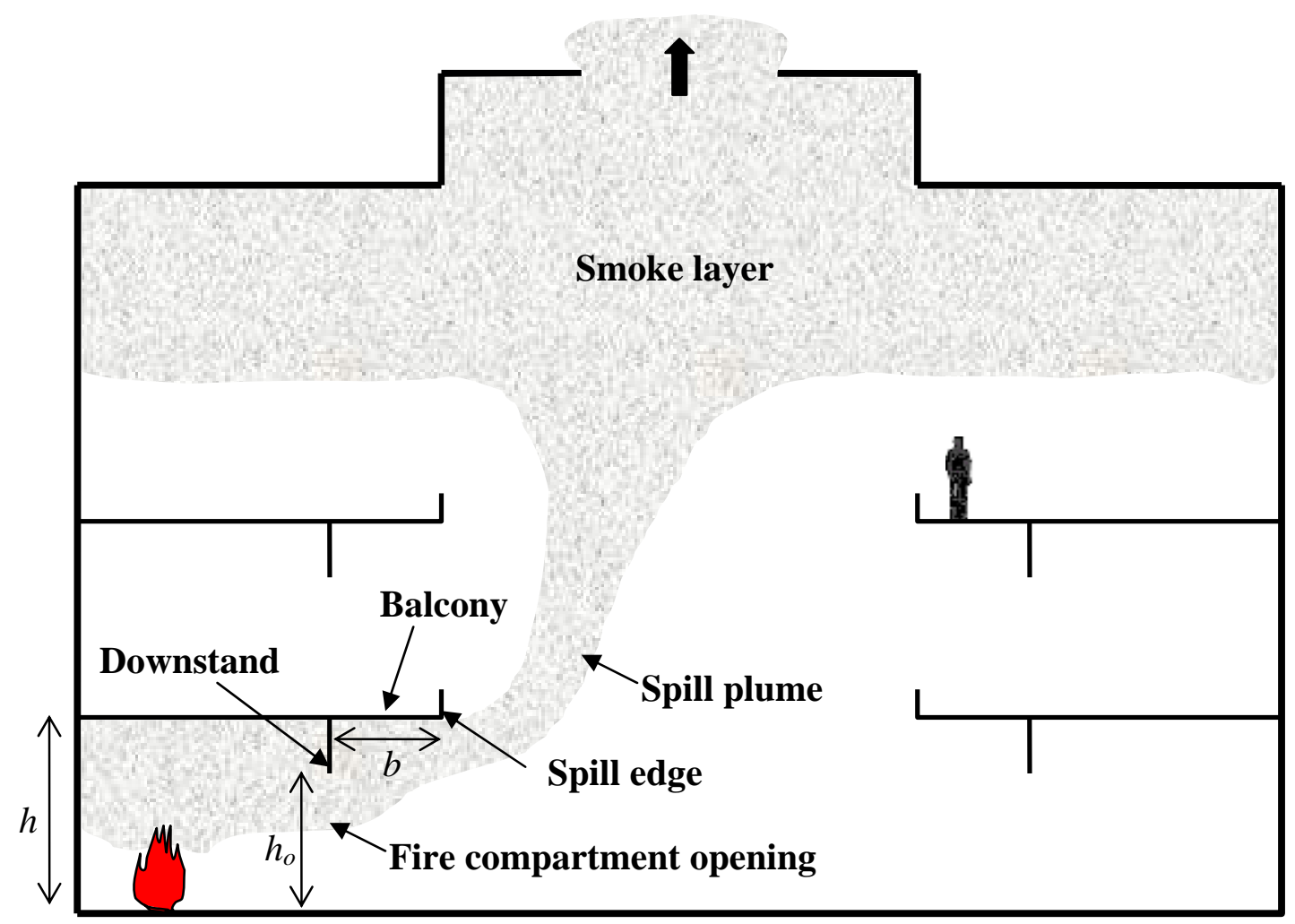

Figure 1. Smoke flow from a compartment opening with a higher projecting balcony, and the subsequent balcony spill plume produced

Unfortunately, there has been little work explicitly studying entrainment of air into smoke flow from a compartment opening to a higher projecting balcony. Morgan and Hansell [1] referenced unpublished work by Marshall, which had identified that this additional entrainment, when expressed as a percentage of the mass flow of gases at the compartment opening, varied from $73 \%$ for a $7 \mathrm{~m}$ wide opening to approximately $150 \%$ for a $14 \mathrm{~m}$ wide opening. This indicated that the amount of entrainment varied with the precise geometry involved. As there was insufficient data to accurately quantify the amount of entrainment for all likely geometries, an entrainment value of $100 \%$ was proposed as being representative for most cases. Therefore, for the purposes of engineering design, Morgan and Marshall proposed that the mass flow rate of gases at the spill edge should be taken to be twice that at the compartment opening [see Equation 1]. It was recognised that this assumption was crude and further work was necessary to further quantify this entrainment.

$$
M_{b}=2 M_{w}
$$


More recent work has been carried out in an attempt to better quantify this entrainment. An iterative calculation method was initially developed by Hansell [2] to determine the mass flow rate of gases at the spill edge for this scenario. This method was derived from limited full scale experimental data obtained from fires within a relatively narrow compartment opening. In all cases, the compartment opening had a width which was equal to the width of the spill edge. However, more recent work by Garrad [3] has shown that this method is only reliable if applied to similar geometries from which the method was derived. Garrad recommended that until further research was carried out, the guidance given by Equation 1 should remain as a conservative estimate for design purposes. This advice is currently contained in guidance for the design of SHEVS in atrium buildings [4].

To improve the available guidance to designers of SHEVS, this paper describes further research to characterise the amount of air entrainment into these flows for a variety of compartment openings. This work aims to develop a simple empirical correlation to accurately predict the mass flow rate of gases at the spill edge.

\section{Approach}

The technical approach for this study was a combination of Computational Fluid Dynamics (CFD) modelling and physical scale modelling. CFD modelling was the primary approach used for this study, with physical scale modelling being used for selected tests to assess the validity of the CFD predictions.

\section{Fire Dynamics Simulator (FDS)}

The CFD model used in this work was Fire Dynamics Simulator (FDS) developed by the National Institute of Standards and Technology (NIST). This model solves a form of the Navier-Stokes equations appropriate for low speed, thermally driven flows typically generated by smoke and heat transport from fires. The fundamental equations and the numerical algorithm within the model are given by McGrattan et al [5] and are not repeated herein. In this study, FDS was set to treat turbulence by means of the Smagorinsky form of the Large Eddy Simulation (LES). The results of the model have been visualised using the post processing tool, Smokeview, developed by Forney and McGrattan [6]. 


\section{Physical scale modelling}

This approach is well established and has been used in many studies of smoke movement in buildings. The approach described in this paper was primarily developed at the Fire Research Station in the UK [7] and typically takes the form of reduced scale fires within a physical model. Measurements are generally made of temperature, velocity and gas concentrations, in addition to visual observations. To ensure that the results can be extrapolated to full scale, the physical scale model used in this study was designed to meet the scaling principles set out by Thomas et al [7]. This is effectively a modified Froude number scaling and requires that the equivalent flows are fully turbulent on both full and model scale.

Dimensional relationships between fluid dynamic variables, which can be derived from first principles, are described elsewhere [8]. These relationships can be simplified by holding one of these variables constant to derive the scaling laws. For experimental modelling, it is convenient to keep the temperature above ambient equal on both full and model scale. Hence, the same temperature must apply to the corresponding points in the flow system, irrespective of scale. The scaling laws can then be described by,

$$
\begin{aligned}
& Q \propto L^{5 / 2} \\
& M \propto L^{5 / 2} \\
& V \propto L^{5 / 2} \\
& u \propto L^{1 / 2}
\end{aligned}
$$

and the time scale $\tau$, which is described for the flow system by,

$$
\tau \propto \frac{L}{u} \propto L^{1 / 2}
$$

It should be noted that all of the above applies only to a flow that is fully turbulent and is driven by buoyancy forces alone. The above scaling laws do not describe either conductive or radiative heat transfer processes. If either is present to a significant extent in the flow system, the scaling laws given here cannot be applied. 


\section{The Experiment}

\section{The physical scale model}

The apparatus used for this work was a $1 / 10^{\text {th }}$ physical scale model (see Figure 2). The model simulated a fire within a compartment from which a higher projecting balcony extended. The fire compartment was constructed from $20 \mathrm{~mm}$ thick ceramic fibre insulation (CFI) board with a $2 \mathrm{~mm}$ thick steel substrate on each external face. A $0.3 \mathrm{~m}$ broad balcony constructed from $10 \mathrm{~mm}$ thick CFI board with a $2 \mathrm{~mm}$ thick steel substrate on its upper face, was attached to the fire compartment opening and extended across its full width. The fire compartment was modified such that a downstand was present at the compartment opening prior to the spill edge. This created the presence of a higher projecting balcony beyond the compartment opening. There were 2 downstands used, $0.1 \mathrm{~m}$ and $0.2 \mathrm{~m}$ deep. Each downstand was generally made from $10 \mathrm{~mm}$ thick CFI board, located $0.3 \mathrm{~m}$ prior to the spill edge. The width of the compartment opening was also adjusted by inserting $10 \mathrm{~mm}$ thick CFI boards, of the desired width, beneath the downstand. Moveable channelling screens made from $10 \mathrm{~mm}$ thick CFI board, occupying the full breadth of the balcony, were located on either side of the compartment opening. The channelling screens were used to provide reasonably constant temperature and velocity profiles across the width of the flow at the opening. This enabled the mass flow rate of gases to be determined from a single velocity and temperature traverse through the smoke layer. The channelling screens occupied the full height of the fire compartment as in previous work $[9,10]$. In reality, these channelling screens would not occupy the full height of the compartment, but would be deep enough to contain the approach flow beneath the balcony. However, in the experiment, the channelling screens were made full height to contain all possible approach flows for the range of conditions studied. The flow conditions at the compartment opening are likely to be similar, either when using full height or short channelling screens, provided that the approach flow is contained within the screens. The technique of using deep channelling screens to encompass a range of approach flow layer depths has been successfully used in previous work [11]. 


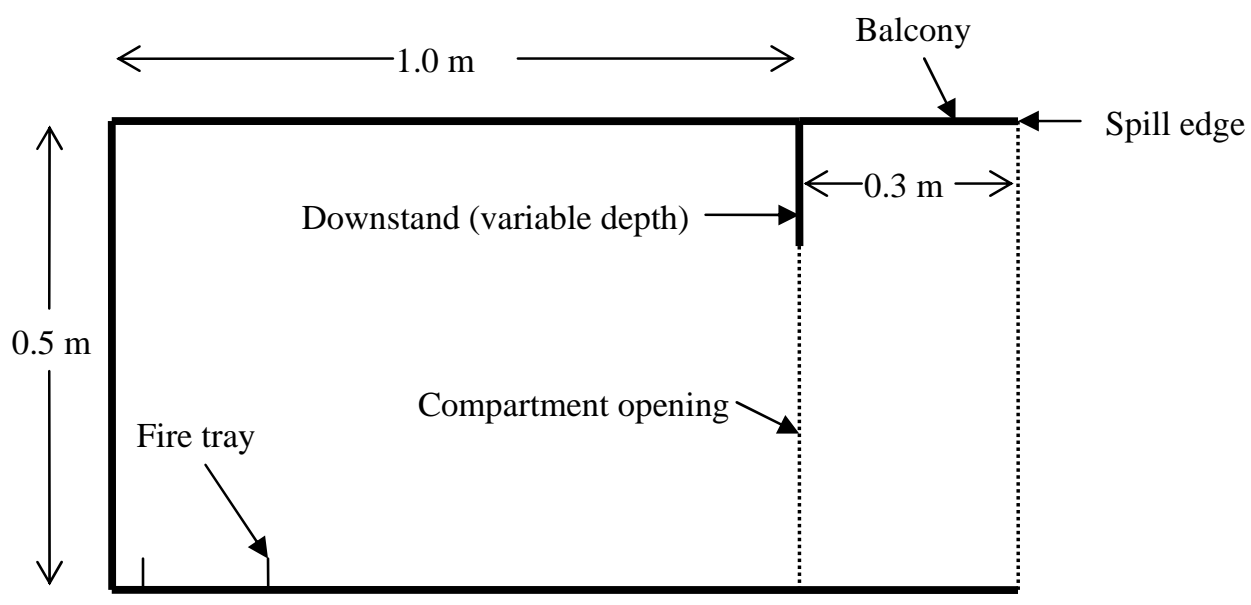

Section

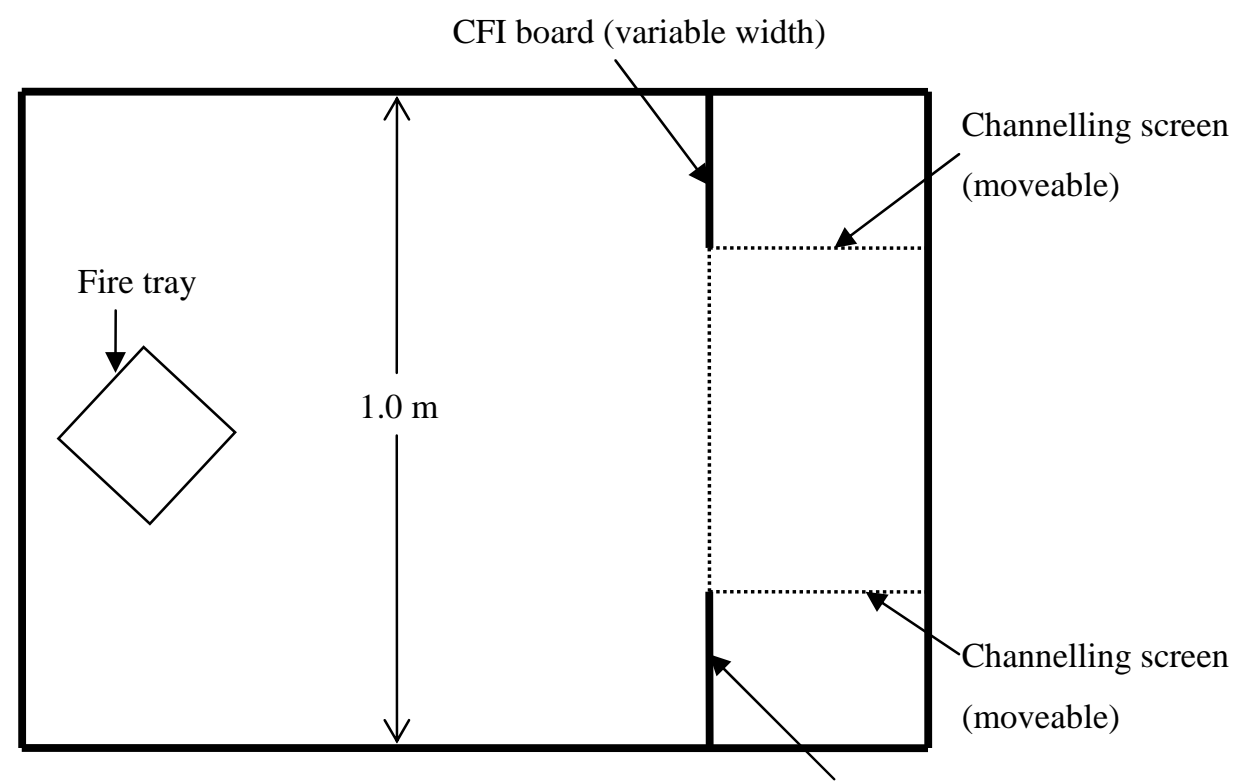

CFI board (variable width)

Plan

Figure 2. Schematic drawing of the $1 / 10^{\text {th }}$ physical scale model

A steady-state fire source was generated by supplying Industrial Methylated Spirits (IMS) into a metal tray within the fire compartment at a controlled and measured rate. The metal tray was located at the rear of the fire compartment. The tray was tilted toward the back of the compartment, so that the fuel surface remained reasonably uniform and automatically adjusted to match the burning rate to the inflow of fuel. The tray was $0.25 \mathrm{~m}$ by $0.25 \mathrm{~m}$ by $0.015 \mathrm{~m}$ high. The hot gases produced from the fire 
were visualised by injecting smoke from a commercial smoke generator into the fire compartment.

\section{Instrumentation and measurements}

The gas temperatures in the model were measured using $0.5 \mathrm{~mm}$ diameter bare wire chromel/alumel (K-type) thermocouples. Thermocouples were positioned at various locations in the model (see Figure 3), as follows:

- 1 column of 16 thermocouples (Column A) located centrally beneath the downstand at the compartment opening

- 1 column of 18 thermocouples (Column B) located centrally beneath the spill edge

- An array of 5 thermocouples (Array A) spaced equally across the width of the compartment opening, projecting $10 \mathrm{~mm}$ below the edge of the downstand

- An array of 5 thermocouples (Array B) spaced equally across the width of the spill edge, projecting $10 \mathrm{~mm}$ below the edge of the balcony

- 1 thermocouple located next to each pitot-static tube when carrying out velocity traverses of the smoke layer at the compartment opening and at the spill edge.

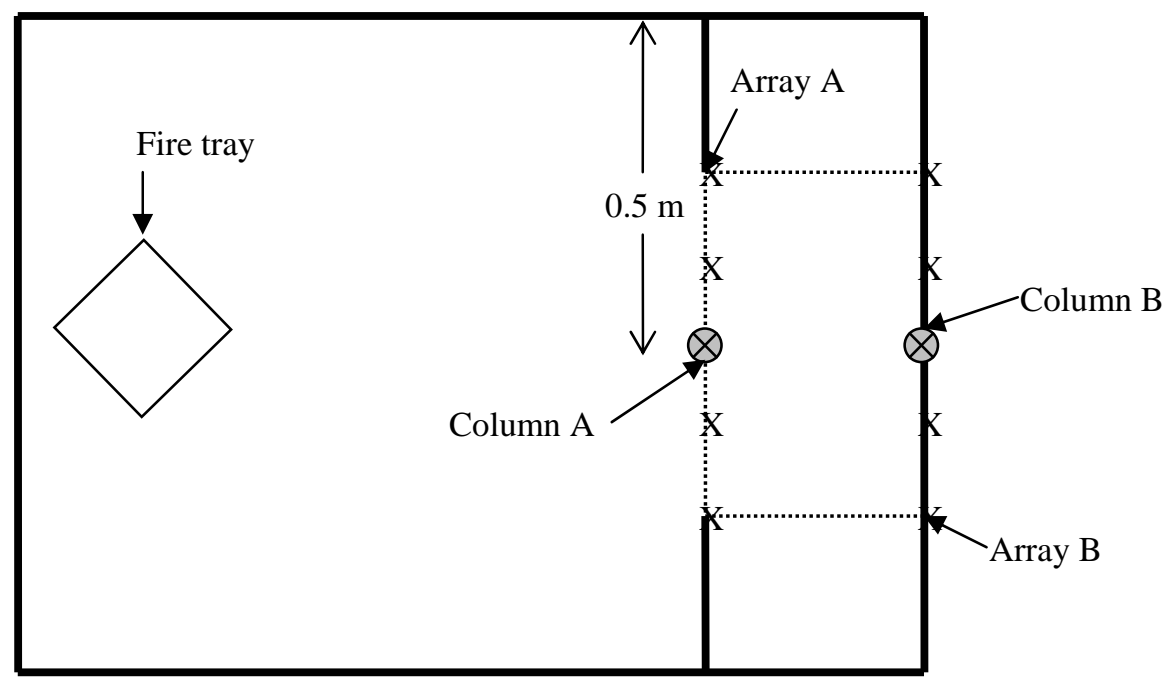

Plan

$\mathrm{X}$ Thermocouple

$\bigotimes$ Thermocouple column

Figure 3. Thermocouple locations 
Vertical velocity and temperature profiles of the buoyant gas layer flow at the compartment opening and at the spill edge were made using a pitot-static tube and a thermocouple. The pitot-static tube was located in a central position at each location and was connected to a sensitive pressure transducer. Vertical velocity and temperature measurements were made every $10 \mathrm{~mm}$ until the base of the smoke layer was reached in each location. This measurement allowed the mass flow rate of gases at the compartment opening $\left(M_{w}\right)$ and at the spill edge $\left(M_{b}\right)$ to be determined. The total mass flow rate of gases was determined by performing an integration under the curve of $w_{o} \rho u$ with respect to the depth of the gas layer. Velocity measurements were also carried out across the width of the gas flow at the compartment opening and at the spill edge (10 mm below the edge) to examine homogeneity of the flow.

Visual observations of each test were carried out. This included the smoke behaviour and the layer depth at the compartment opening and at the spill edge. Photographic records were also made for selected tests. All experimental measurements were made once relatively steady state conditions had been reached within the fire compartment.

\section{Parameter variation}

As CFD modelling was primarily used to study this aspect of the work, only a selected number of experiments were carried out. The height of the fire compartment, the breadth of the balcony and the size of the fire remained fixed for all of the experiments carried out. The downstand depth was varied. Two downstand depths were used, $0.1 \mathrm{~m}$ and $0.2 \mathrm{~m}$ deep respectively. This in turn varied the height of the compartment opening. The width of the compartment opening was also varied so that a range of aspect ratios of compartment opening could be examined.

\section{FDS Modelling}

\section{Modelled geometry}

A greater range of fire compartment geometries were examined using FDS than those carried out experimentally. As in the experiment, the fire compartment was modelled such that a downstand was present at a compartment opening prior to a higher projecting balcony. A variety of downstand, balcony and fire compartment opening 
geometries were examined. Full height channelling screens were also modelled on either side of the compartment opening. In general, the walls, ceiling and balcony of the fire compartment were assumed to be made of $20 \mathrm{~mm}$ thick CFI board. The channelling screens, downstands and walls to reduce the compartment opening width, were assumed to be made from $10 \mathrm{~mm}$ thick CFI board as in the experiment.

The computational domain contained a volume which was $1.8 \mathrm{~m}$ long by $1.0 \mathrm{~m}$ wide by $1.0 \mathrm{~m}$ high. The domain extended $0.5 \mathrm{~m}$ above and $0.5 \mathrm{~m}$ beyond the spill edge so that the initial gas flow beyond the fire compartment could be examined. In an attempt to minimise any inaccuracies in the FDS prediction, preliminary simulations were carried out to determine the minimum grid size possible within the computational domain. It should be noted that a coarse grid size can give rise to misleading results. Therefore, the grid size was systematically reduced (hence, increasing the total number of cells in the domain) until it was not possible to achieve a result due to limitations in the available computing power. The minimum grid size to achieve a result was found to be $20 \mathrm{~mm}$. Thus, a grid size of $20 \mathrm{~mm}$ was used for all of the simulations which resulted in a total number of 225,000 grid cells within the computational domain. The fire source assumed in FDS was an ethanol pool fire, as used in the experiment.

FDS predicted gas temperatures by assuming two arrays of five thermocouples equally spaced across the width of the compartment opening (under the downstand) and across the spill edge (under the balcony). These thermocouples were situated 10 $\mathrm{mm}$ below the edge and were used to determine if the temperature profile was reasonably homogeneous across the flow. Velocity predictions were also made at these locations. Gas temperatures were also predicted by assuming a column of thermocouples being present in a central location at the compartment opening and at the spill edge. The thermocouples on each column were equally spaced at an interval of $10 \mathrm{~mm}$ from floor to ceiling level. Velocity predictions were also made at these locations. Velocity and temperature slices were also generated within FDS in an x-z plane (long length) centrally through the compartment. These slices provided an overall velocity and temperature map for a plane. 


\section{Parameter variation}

For all of the simulations modelled, the height of the fire compartment remained fixed at $0.5 \mathrm{~m}$ to represent the height of a typical shop unit ( $5 \mathrm{~m}$ full scale). The total heat output of the fire was varied by altering the assumed size of the fire tray in FDS. For the majority of simulations, the fire size had a nominal, steady-state total heat output of $10.3 \mathrm{~kW}$. However, for selected tests, the fire size was varied to either 6 or $16 \mathrm{~kW}$. The width of the fire compartment opening was also varied. Five different opening widths were examined in total $(0.2 \mathrm{~m}, 0.4 \mathrm{~m}, 0.6 \mathrm{~m}, 0.8 \mathrm{~m}$ and $1.0 \mathrm{~m}$ respectively). The effect of balcony breadth was also examined. For the majority of the simulations, the balcony breadth was fixed at $0.3 \mathrm{~m}$. However for selected tests, the balcony breadth was varied to either $0.2 \mathrm{~m}$ or $0.5 \mathrm{~m}$. The depth of the downstand was also varied. Five different downstand depths were examined, $0.1 \mathrm{~m}, 0.16 \mathrm{~m}, 0.2 \mathrm{~m}, 0.25 \mathrm{~m}$ and $0.3 \mathrm{~m}$ respectively. This in turn varied the height of the fire compartment opening. The respective changes to the compartment opening geometry in turn varied the mass flow rate, convective heat output and the depth of the gas layer at the compartment opening and at the spill edge.

\section{Results and Discussion \\ Comparison of the FDS prediction with the experiment}

To enable an assessment to be made of the validity of the FDS predictions, a comparison was made with the experimental results in terms of gas temperature and velocity. Figures 4 and 5 show a comparison between the FDS prediction and the experiment for the temperature and velocity profiles of the gas layer at the spill edge respectively. Figures 4 and 5 show that there is very good agreement between the FDS prediction and the experiment at this location. The profiles follow a similar shape, indicating that FDS also accurately predicts the depth of the gas layer at the spill edge. In general, the agreement between the FDS predictions and the experimental results were generally very good for all of the comparisons carried out, both at the spill edge and at the compartment opening. This provided the confidence in the FDS predictions to develop an empirical correlation to predict the entrainment of air into a flow from a compartment opening to a higher projecting balcony, and hence, the subsequent mass flow rate of gases at the spill edge. 


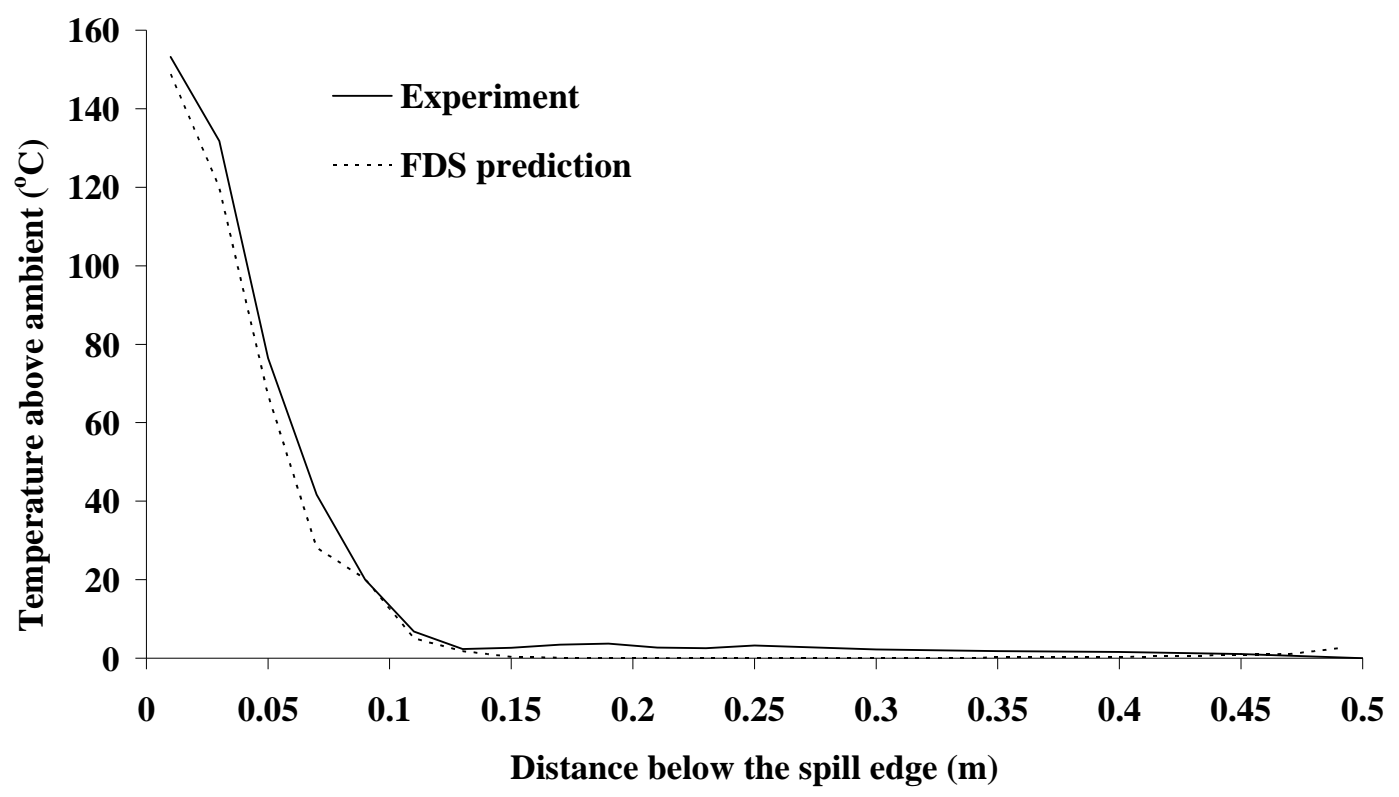

Figure 4. Comparison between the FDS prediction and the experiment of the temperature of the gas layer at the spill edge (1.0m wide opening, $0.1 \mathrm{~m}$ downstand)

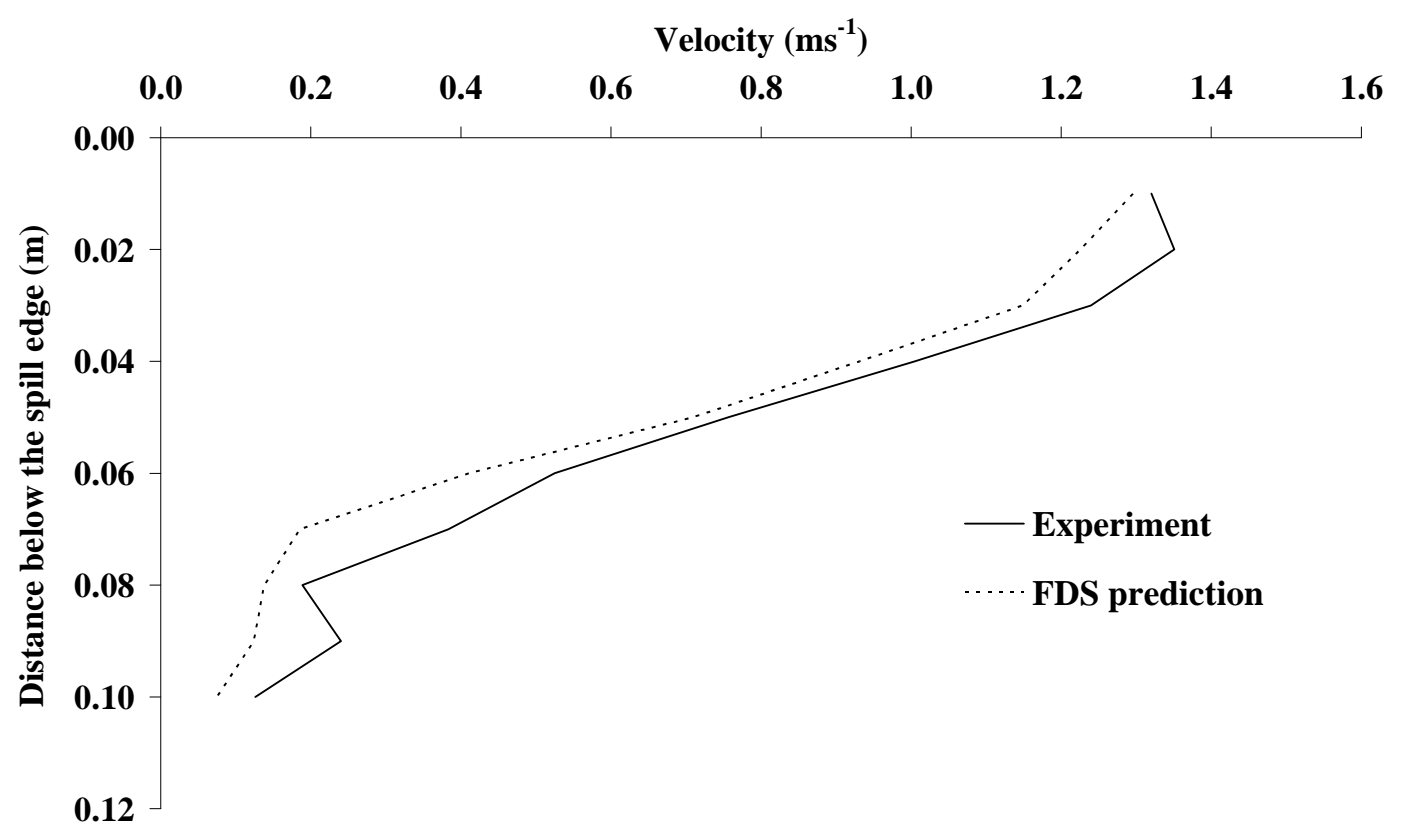

Figure 5. Comparison between the FDS prediction and the experiment of the velocity of the gas layer at the spill edge (1.0 $\mathrm{m}$ wide opening, $0.1 \mathrm{~m}$ downstand) 


\section{Flow behaviour}

The flow behaviour described here is primarily based on the FDS simulation results which were similar to the behaviour observed from the physical scale model experiments. The Smokeview output from the FDS simulations have been used to show the flow behaviour. Figure 6 shows the gas layer flow beneath the downstand at the compartment opening before rising to form a horizontally flowing layer beneath the balcony. This layer then rises as a plume as it flows beyond the spill edge.
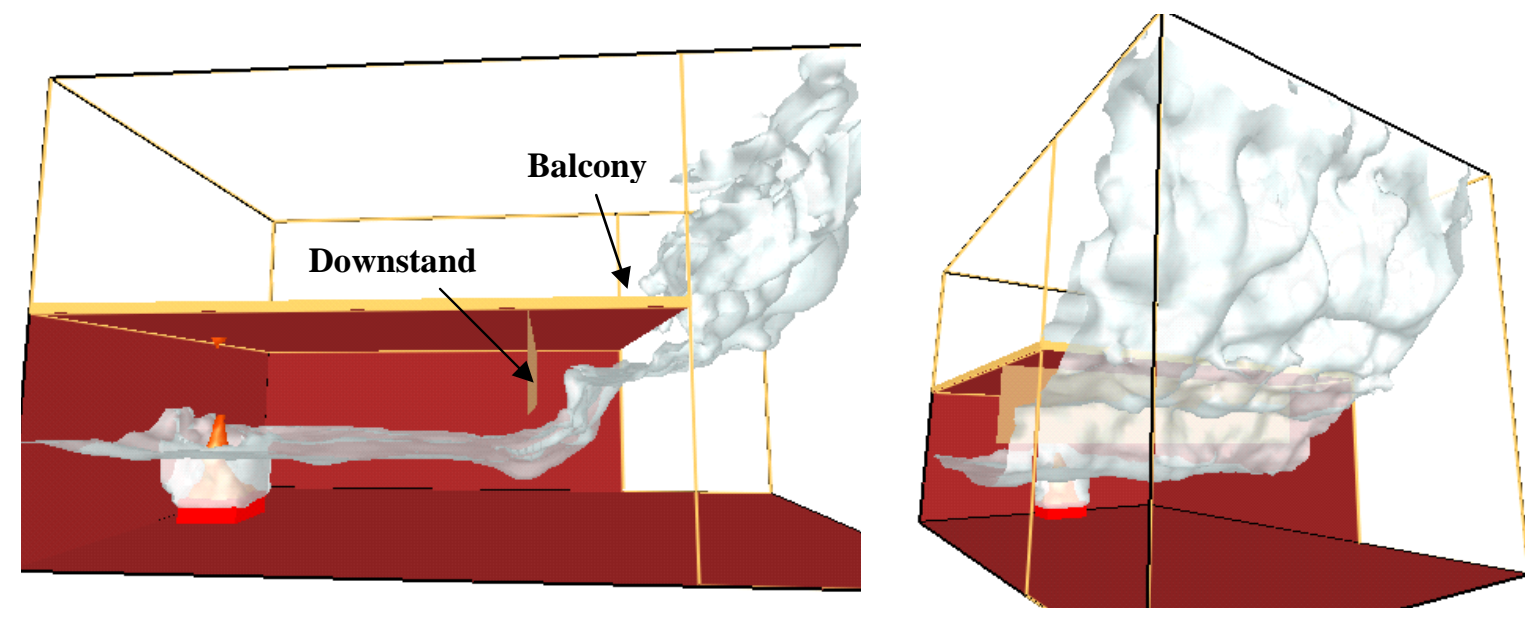

Figure 6. Flow behaviour from a compartment opening to a higher projecting balcony

Figure 7 shows the detailed nature of the flow between the compartment opening and the spill edge in terms of velocity vectors. Figure 7 shows the flow rising from beneath the downstand as a discernable “jet” before flowing as a horizontally moving layer toward the spill edge. It also shows the recirculation of the flow behind this "jet" close to the downstand. 


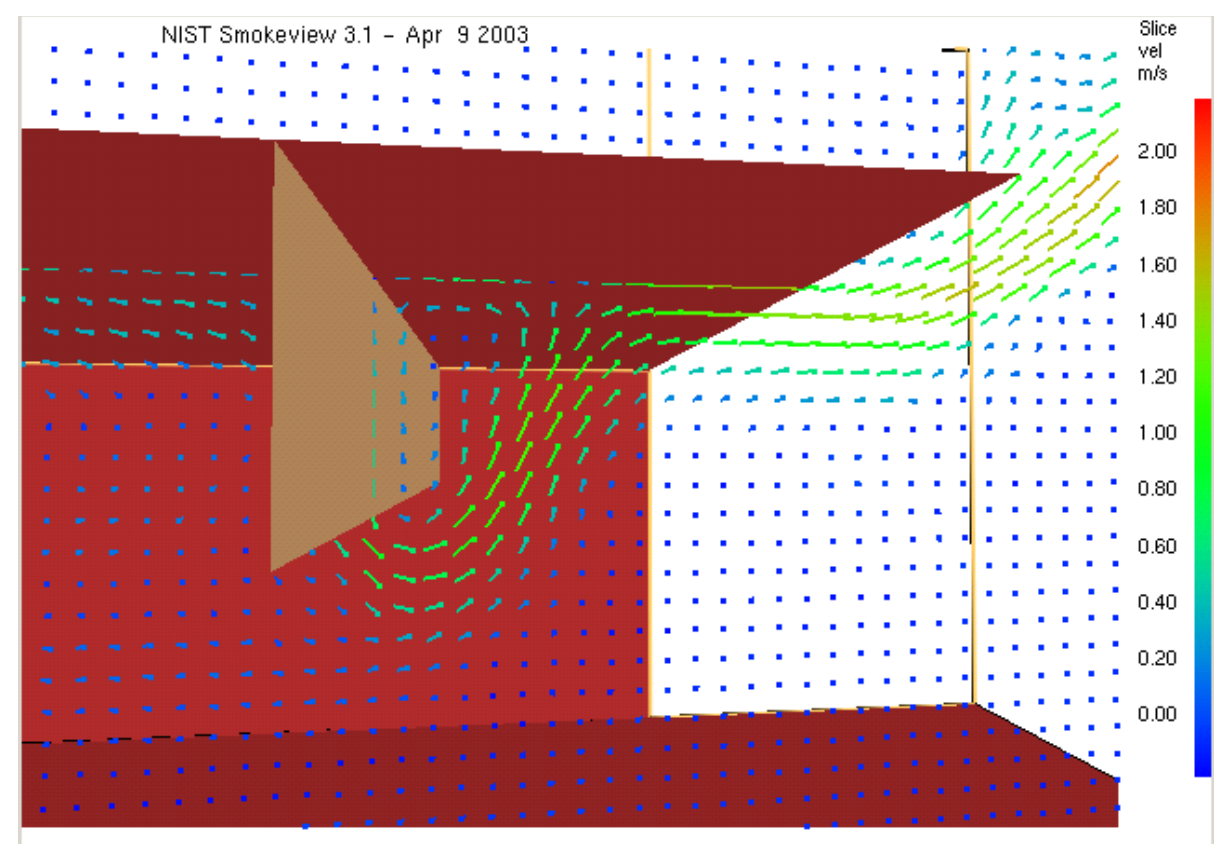

Figure 7. Velocity vectors of flow from a compartment opening to a higher projecting balcony

The behaviour of the flow from a narrow compartment opening was generally similar to that described above. However, the flow appeared to have and increased amount of horizontal projection from the opening compared to a wider opening.

The flow behaviour for all of the simulations described above was for a balcony with a breadth of $0.3 \mathrm{~m}$ ( $3 \mathrm{~m}$ full scale). For this breadth of balcony, the flow from the compartment opening generally transformed into a horizontally moving flow beneath the balcony before spilling at the free edge. This behaviour was also observed for those simulations which examined a balcony breadth of $0.5 \mathrm{~m}$.

However, simulations which examined a balcony breadth of $0.2 \mathrm{~m}$ resulted in a flow which projected beyond the balcony, without a horizontally flowing layer forming beneath. For this scenario, the effective spill edge will be at the top of the compartment opening, with the mass flow rate of gases at the compartment opening being an appropriate input parameter for spill plume calculations. 


\section{Mass flow rate of gases at the spill edge}

In the absence of any underlying theory, the FDS results were correlated in various ways in an attempt to develop an empirical correlation to predict the mass flow rate of gases at the spill edge. Those parameters which were expected to influence the entrainment of air into these flows were included in the correlations. The following parameters were used:

- Mass flow rate of gases at the compartment opening $\left(M_{w}\right)$

- Mass flow rate of gases at the spill edge $\left(M_{b}\right)$

- Width of the compartment opening $\left(w_{o}\right)$

- Height of the compartment opening $\left(h_{o}\right)$

- Height of the compartment $(h)$

The results for a flow beneath a $0.2 \mathrm{~m}$ broad balcony were not included since the nature of this flow was fundamentally different from all of the other simulations.

Figure 8 shows the correlated results from the simulations when $\left(\frac{M_{b} w_{o}}{M_{w} h}\right)$ was plotted with respect to $\left(\frac{h_{o}}{w_{o}}\right)$. In this case, all of the predictions conveniently collapse down onto a single relationship described by a power law which is non-dimensional in nature. This relationship appears to be versatile, as it applies to a wide range of compartment opening geometries (i.e. aspect ratios) and downstand depths. It also appears to be independent of the heat output of the fire which was also varied in the simulations. 


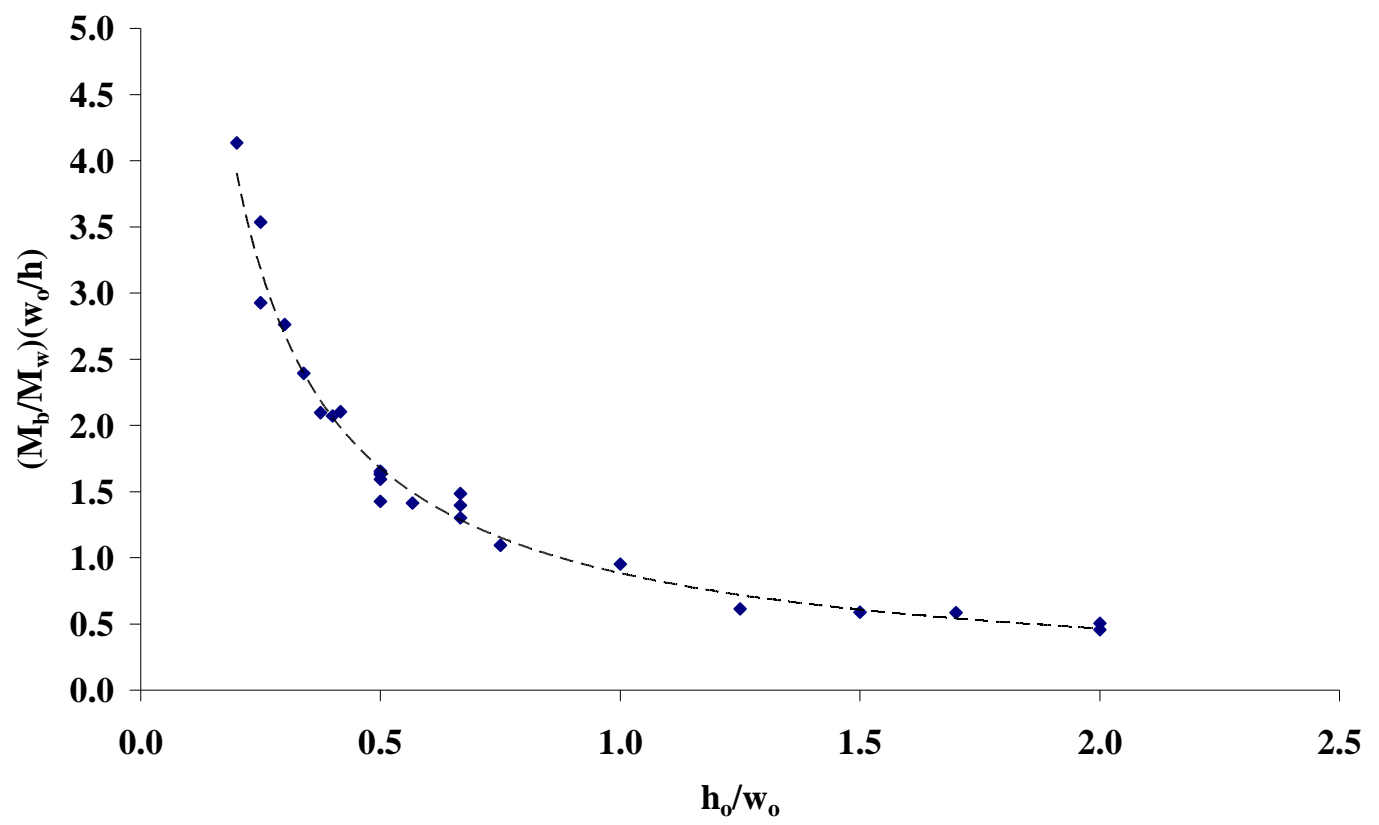

Figure 8. Correlated FDS predictions in the form of a power law

It appears that the line of best fit to describe this relationship could be used as an empirical correlation to predict the mass flow rate of gases at the spill edge. To assess the validity of this relationship, the experimental results were also plotted in a similar manner and compared with the FDS predictions.

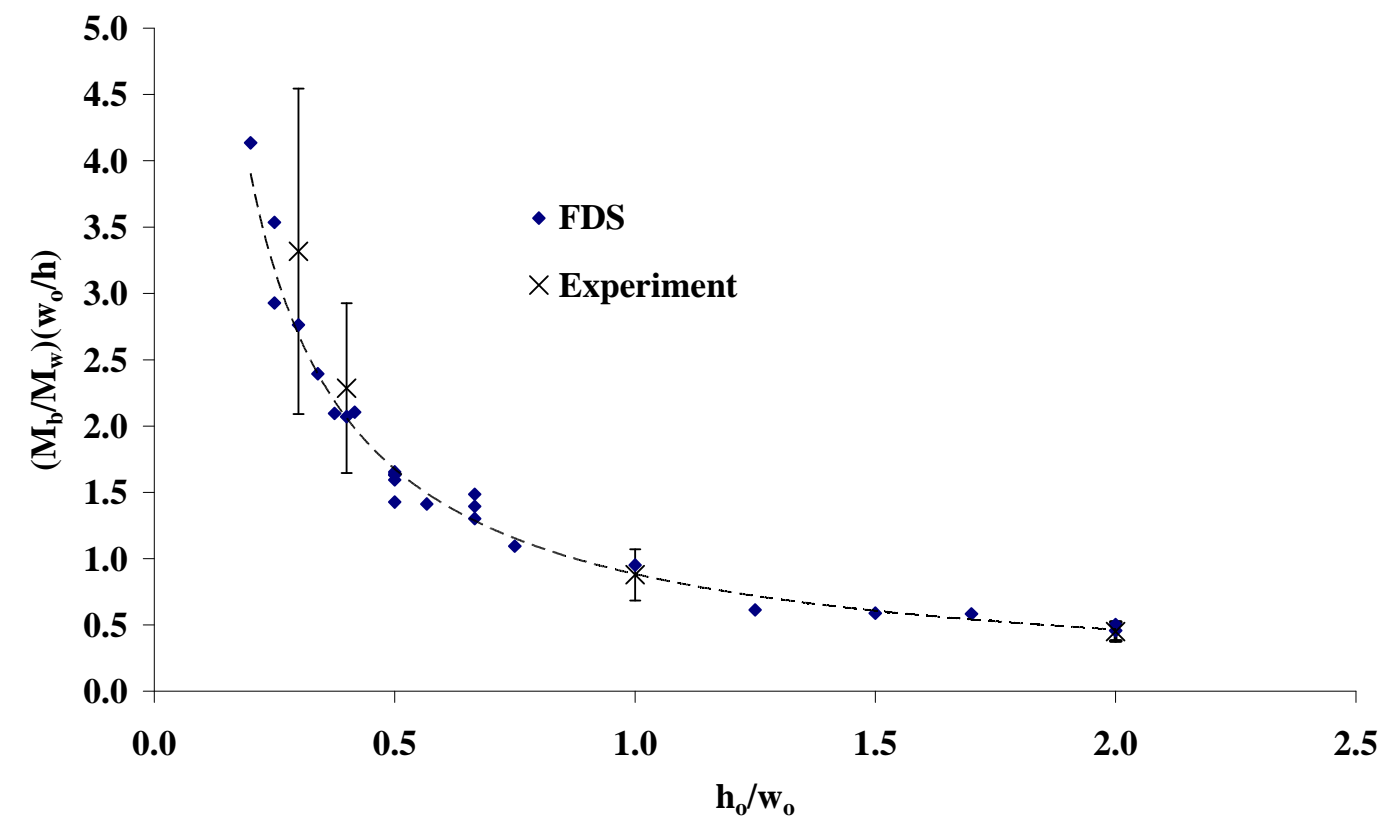

Figure 9. Comparison of correlated FDS predictions and experimental results 
Figure 9 shows that the experimental measurements appear to generally obey the power law given by the FDS predictions. This provides further confidence for the use of this empirical relationship as a calculation method for design purposes.

\section{Empirical correlation for design purposes}

Equation 4 gives an empirical correlation to predict the entrainment of air from a compartment opening to a higher projecting balcony, and hence, the mass flow rate of gases at the spill edge. This was determined from the line of best fit of the power law relationship from the FDS predictions shown in Figure 8.

$$
M_{b}=0.89\left(\frac{h_{o}}{w_{o}}\right)^{-0.92}\left(\frac{h M_{w}}{w_{o}}\right)
$$

Since the empirical correlation is non-dimensional in nature, Equation 4 appears to be versatile and simple to use. It necessarily requires the calculation of the mass flow rate of gases at a compartment opening, which can be determined using simple wellestablished methods given either by Morgan et al [4], Thomas et al [7] or Quintiere et al [11]. The other parameters are physical, and are likely to be specified in the design. However, since Equation 4 is empirical in nature, there are constraints on its use which are dependent upon the range of conditions in which the correlation was derived. Initial limits were set on this equation [12] but subsequent parametric analysis found that the following limits apply, such that

$$
1.16<\left(\frac{h_{o}}{w_{o}}\right)^{-0.92}\left(\frac{h}{w_{o}}\right)<2.23
$$

Equation 4 only applies to a flow where a horizontally flowing layer forms beneath the higher projecting balcony. The criterion for the required breadth of balcony to achieve this flow, based on the on the conditions studied, is given by Equation 6 .

$$
\left(\frac{h}{h_{o}}\right)\left(\frac{b}{h-h_{o}}\right) \geq 2.5
$$


Equation 4 applies to a flow which is channelled, and where the width of the compartment opening is the same as the width of the spill edge. It applies to a wide range of typical compartment opening geometries such as a doorway opening (e.g. 2.0 $\mathrm{m}$ high by $1.0 \mathrm{~m}$ wide opening) to a wide shop unit (e.g. $10 \mathrm{~m}$ wide by $2 \mathrm{~m}$ high opening). It also applies for a compartment opening with a higher projecting balcony generally greater than $2 \mathrm{~m}$ in breadth.

\section{Comparison with the Hansell method}

In an attempt to provide further confidence in the empirical correlation given by Equation 4, a comparison was made with the results produced by the Hansell method [2] to predict the mass flow rate of gases at a spill edge. The analysis carried out by Garrad [3] was used to identify two scenarios in which the Hansell method converged to a solution. A comparison was then made between the results produced from the Hansell method and Equation 4 for each scenario. The two scenarios examined by Garrad were:

- Scenario 1 - A 1 MW fire within a small cellular office

- Scenario 2 - A 5 MW fire within a large area shop unit

Garrad used a calculation technique given by Morgan et al [4] to determine the mass flow rate of gases at the compartment opening for each scenario. Table 1 shows the assumed geometries and the calculated mass flow rate of gases at the compartment opening.

\begin{tabular}{|c|c|c|c|c|}
\hline Scenario & $\begin{array}{c}\mathbf{h} \\
\mathbf{( m )}\end{array}$ & $\begin{array}{c}\mathbf{h}_{\mathbf{0}} \\
\mathbf{( m )}\end{array}$ & $\begin{array}{c}\mathbf{w}_{\mathbf{0}} \\
\mathbf{( m )}\end{array}$ & $\begin{array}{c}\mathbf{M}_{\mathbf{w}} \\
\mathbf{( k g s}^{-\mathbf{1}} \mathbf{)}\end{array}$ \\
\hline 1 & 4.0 & 3.0 & 6.0 & 11.2 \\
\hline 2 & 4.0 & 3.0 & 3.0 & 7.9 \\
\hline
\end{tabular}

Table 1. Assumed geometries and calculated values of $\mathbf{M}_{w}$ for Scenarios 1 and 2

The subsequent mass flow rate of gases at the spill edge, determined using the Hansell method and Equation 4, are given in Table 2 for each scenario examined. 


\begin{tabular}{|c|c|c|}
\hline Scenario & $\begin{array}{c}\text { Hansell method }\left(\mathbf{M}_{\mathbf{b}}\right) \\
\left(\mathbf{k g s}^{-\mathbf{1}}\right)\end{array}$ & $\begin{array}{c}\text { Equation 4 }\left(\mathbf{M}_{\mathbf{b}}\right) \\
\left.\mathbf{k g s}^{\mathbf{- 1}}\right)\end{array}$ \\
\hline 1 & 13.0 & 12.6 \\
\hline 2 & 8.7 & 9.4 \\
\hline
\end{tabular}

Table 2. Calculated values of $M_{b}$ using the Hansell method and Equation 4

Table 2 shows that for each scenario, there is good agreement between the Hansell method and Equation 4 in the prediction of the mass flow rate of gases at the spill edge. Since the Hansell method is recognised to give a reliable result for geometries similar to that in which the method was derived (as is the case for Scenarios 1 and 2), the good agreement gives further support for the use of Equation 4 as an empirical correlation for design purposes to predict the mass flow rate of gases at the spill edge.

\section{General}

The calculated mass flow rate of gases at the compartment opening $\left(M_{w}\right)$ and at the spill edge $\left(M_{b}\right)$ from the FDS predictions are given in Table 3 . The results are presented in terms of the time averaged mean value with associated standard errors. The ratio of $\left(M_{b} / M_{w}\right)$ is also included for comparison with the current guidance on entrainment of air into these flows. Analysis of the results shows that, in general, the current guidance on the entrainment of air into a flow from a compartment opening to a higher projecting balcony (i.e. $M_{b}=2 M_{w}$ ) is conservative. The majority of the simulations determined values of $M_{b}$ which were much smaller than $2 M_{w}$. However, for one particular simulation (Simulation 17), the value of $M_{b}$ was equal to $2 M_{w}$. This result suggests that entrainment of air into these flows is greatest for wide compartment openings with a deep downstand.

In general, it appears that the use of Equation 4 to predict the mass flow rate of gases at the spill edge, will give rise to a more cost effective smoke ventilation design. 


\begin{tabular}{|c|c|c|c|}
\hline Simulation & $\begin{array}{c}\mathbf{M}_{\mathbf{w}} \\
\mathbf{k g g s}^{-1} \mathbf{)}\end{array}$ & $\begin{array}{c}\mathbf{M}_{\mathbf{b}} \\
\mathbf{k g g s}^{-1} \mathbf{)}\end{array}$ & $\mathbf{M}_{\mathbf{b}} / \mathbf{M}_{\mathbf{w}}$ \\
\hline 1 & $0.0587+/-0.0004$ & $0.0608+/-0.0006$ & 1.0356 \\
\hline 2 & $0.0563+/-0.0004$ & $0.0582+/-0.0005$ & 1.0344 \\
\hline 3 & $0.0463+/-0.0004$ & $0.0539+/-0.0005$ & 1.1625 \\
\hline 4 & $0.0361+/-0.0004$ & $0.0430+/-0.0004$ & 1.1905 \\
\hline 5 & $0.0196+/-0.0003$ & $0.0247+/-0.0003$ & 1.2591 \\
\hline 6 & $0.0517+/-0.0005$ & $0.0619+/-0.0006$ & 1.1968 \\
\hline 7 & $0.0410+/-0.0004$ & $0.0482+/-0.0004$ & 1.1774 \\
\hline 8 & $0.0158+/-0.0002$ & $0.0231+/-0.0003$ & 1.4603 \\
\hline 9 & $0.0468+/-0.0004$ & $0.0646+/-0.0006$ & 1.3815 \\
\hline 10 & $0.0422+/-0.0004$ & $0.0553+/-0.0005$ & 1.3101 \\
\hline 11 & $0.0354+/-0.0003$ & $0.0480+/-0.0004$ & 1.3577 \\
\hline 12 & $0.0255+/-0.0003$ & $0.0348+/-0.0003$ & 1.3675 \\
\hline 13 & $0.0140+/-0.0002$ & $0.0206+/-0.0002$ & 1.4725 \\
\hline 14 & $0.0335+/-0.0003$ & $0.0592+/-0.0005$ & 1.7685 \\
\hline 15 & $0.0272+/-0.0003$ & $0.0477+/-0.0004$ & 1.7531 \\
\hline 16 & $0.0109+/-0.0002$ & $0.0168+/-0.0002$ & 1.5327 \\
\hline 17 & $0.0315+/-0.0003$ & $0.0651+/-0.0006$ & 2.0675 \\
\hline 18 & $0.0269+/-0.0003$ & $0.0493+/-0.0004$ & 1.8299 \\
\hline 19 & $0.0366+/-0.0003$ & $0.0434+/-0.0004$ & 1.1883 \\
\hline 20 & $0.0191+/-0.0002$ & $0.0218+/-0.0002$ & 1.1417 \\
\hline 21 & $0.0299+/-0.0003$ & $0.0397+/-0.0003$ & 1.3279 \\
\hline 22 & $0.0401+/-0.0004$ & $0.0548+/-0.0005$ & 1.3645 \\
\hline 23 & $0.0365+/-0.0003$ & $0.0396+/-0.0004$ & 1.0844 \\
\hline 24 & $0.0525+/-0.0005$ & $0.0650+/-0.0006$ & 1.2379 \\
\hline 25 & $0.0336+/-0.0003$ & $0.0614+/-0.0006$ & 1.8241 \\
\hline & & & \\
\hline
\end{tabular}

Table $3 . \quad$ Summary of the FDS predictions for mass flow rate of gases at the compartment opening and at the spill edge

\section{Conclusions}

The findings of the CFD and physical scale modelling studies provided the following conclusions:

- In general, the current guidance on the entrainment of air into a flow from a compartment opening to a higher projecting balcony is conservative.

- The results suggest that entrainment of air into these flows is greatest for wide openings with a deep downstand.

- An empirical correlation has been determined to predict the entrainment of air into a flow from a compartment opening to a higher projecting balcony, and hence, the subsequent mass flow rate of gases at the spill edge. This correlation only applies to a flow which is channelled, where the width of the 
compartment opening is the same as the width of the spill edge. This correlation is given by,

$$
M_{b}=0.89\left(\frac{h_{o}}{w_{o}}\right)^{-0.92}\left(\frac{h M_{w}}{w_{o}}\right)
$$

With the limits,

$$
1.16<\left(\frac{h_{o}}{w_{o}}\right)^{-0.92}\left(\frac{h}{w_{o}}\right)<2.23
$$

and

$$
\left(\frac{h}{h_{o}}\right)\left(\frac{b}{h-h_{o}}\right) \geq 2.5
$$

\section{Acknowledgements}

The authors would like to thank the following: The Society of Fire Protection Engineers Educational and Scientific Foundation, for providing funding for providing funding for this research. FRS, for allowing the primary author to undertake an 18 month sabbatical to complete this research. Russell Peoples and Grant Dunlop of the University of Canterbury, for their invaluable help with the design and construction of the experimental apparatus. 


\section{Nomenclature}

$b \quad$ Balcony breadth

h Height of compartment

$h_{o} \quad$ Height of compartment opening

L Characteristic linear height of the model

$M \quad$ Mass flow rate of gases

$M_{b} \quad$ Mass flow rate of gases at the spill edge

$M_{w} \quad$ Mass flow rate of gases at the compartment opening

$Q \quad$ Convective heat flux at the spill edge

u Velocity

$V \quad$ Volume flow rate $\left(\mathrm{m}^{3} \mathrm{~s}^{-1}\right)$

$w_{o} \quad$ Width of compartment opening

$\rho \quad$ Density $\left(\mathrm{kgm}^{-3}\right)$

\section{References}

[1] H P Morgan and G O Hansell, "Atrium buildings: calculating smoke flows in atria for smoke control design”. Fire Safety Journal, 12, pp 9-35, 1987.

[2] G O Hansell, "Heat and mass transfer process affecting smoke control in atrium buildings”. PhD thesis, South Bank University, London, 1993.

[3] G Garrad, "Calculations based on the Hansell method for calculating entrainment into hot gases flowing beneath a downstand and rising to a projecting canopy”. Private communication, Building Research Establishment, 1996.

[4] H P Morgan, B K Ghosh, G Garrad, R Pamlitschka, J-C De Smedt and L R Schoonbaert, "Design methodologies for smoke and heat exhaust ventilation", BRE Report 368, 1999.

[5] K B McGrattan, G P Forney, F E Floyd, S Hostikka and K Prasad. "Fire Dynamics Simulator (Version 3) - User Guide”, NISTIR 6784, National Institute of Technology and Standards, 2002. 
[6] G P Forney and K B McGrattan, "User’s guide for Smokeview version 3.1 - a tool for visualizing fire dynamics simulation data”, NISTIR 6980, National Institute of Technology and Standards, 2003.

[7] P H Thomas, P L Hinkley, C R Theobald and D L Simms, "Investigations into the flow of hot gases in roof venting”, Fire Research Technical Paper No 7, London, The Stationary Office, 1963.

[8] H P Morgan, N R Marshall and B M Goldstone, "Smoke hazards in covered multi-level shopping malls: some studies using a model 2-storey mall”, Building Research Establishment Current Paper, CP45/76, BRE, 1976.

[9] G O Hansell, H P Morgan and N R Marshall, "Smoke flow experiments in a model atrium”, BRE Occasional Paper OP55, 1993.

[10] N R Marshall and R Harrison, "Experimental studies of thermal spill plumes”, BRE Occasional Paper, OP1, 1996.

[11] J G Quintiere, W J Rinkinen and W W Jones, “The effects of room openings on fire plume entrainment”, Combustion Science and Technology, 26, pp 1983201, 1981.

[12] R Harrison. "Smoke control in atrium buildings: A study of the thermal spill plume”, Fire Engineering Research Report 04/1, Department of Civil Engineering, University of Canterbury, New Zealand, 2004. 